\title{
APPLICATION OF POTASSIUM FERTILIZER AND TEAK LEAVES DEBRIS FOR ARROWROOT YIELD
}

\author{
Ahmad Ichsan Yunanto ${ }^{1)}$,Supriyono ${ }^{2)}$, Sri Nyoto ${ }^{2)}$ \\ 1) Mahasiswa S1 Program Studi Agroteknologi, Fakultas Pertanian, Universitas Sebelas Maret \\ 2) Staf Dosen Program Studi Agroteknologi, Fakultas Pertanian, Universitas Sebelas Maret \\ Contact Author: ichsan085@gmail.com
}

\begin{abstract}
Arrowroot yield can be used as a substitute for rice. Arrowroot tubers can be utilized to meet the needs of carbohydrates. Potassium fertilizer can help the formation of arrowroot tubers and the formation of arrowroot starch. Arowroot are found wildly grown under teak. This research aims to determine the dose of potassium fertilizer and determine the influence of teak leaf debris on arowrrot yield. This research was held from March to September 2016 in the Agricultural Land UNS Jumantono. The research using Randomized Completely Block Design (RCBD) method. Two separate experiments that $\mathrm{KCl}$ fertilizer application and the application of teak leaf debris dry. $\mathrm{KCl}$ fertilizer treatment given to the arrowroot plant is $\mathrm{KO}\left(0 \mathrm{~g}^{-1}\right.$ plant), $\mathrm{K} 1$ ( $2,4 \mathrm{~g}^{-1}$ plant), $\mathrm{K} 2\left(4,8 \mathrm{~g}^{-1}\right.$ plant), $\mathrm{K} 3\left(7,2 \mathrm{~g}^{-1}\right.$ plant $)$ and $\mathrm{K} 4\left(9,6 \mathrm{~g}^{-1}\right.$ plant). Debris leaves of teak treatment given the arrowroot plant is A0 (0 $\mathrm{g}^{-1}$ plant), A1 (20 g plant), A2 (40 g $\mathrm{g}^{-1}$ plant), A3 (60 g plant) and A4 (80 g plant). The results showed that the fertilizer $\mathrm{KCl} 4,8$ $\mathrm{g}^{-1}$ plant tends to increase arrowroot yields. Adding teak leaf debris $80 \mathrm{~g}^{-1}$ plant tends to increase the number and weight of arrowroot tubers.
\end{abstract}

Keyword: tubers, starch, carbohydrates, alellopathy

AGROTECHNOLOGY RESEARCH JOURNAL

Yunanto Al, Supriyono, Nyoto S. 2017. Application of potassium fertilizer and teak leaves debris for arrowroot yield. Agrotech Res J 1(1): 41-45.

Yunanto AI, Supriyono, Nyoto S. 2017. Pemberian pupuk kalium dan seresah daun jati terhadap hasil garut. Agrotech Res J 1(1): 41-45.

\section{PENDAHULUAN}

Konsumsi pangan di Indonesia masih didominasi oleh beras. Dengan banyaknya konsumsi beras masyarakat di Indonesia, maka kebutuhan akan beras pun meningkat. Oleh karena itu, dibutuhkan alternatif bahan pangan yang dapat menggantikan beras atau sebagai makanan pokok lain selain beras. Di Indonesia sendiri, banyak ragam pangan lokal yang berpotensi sebagai sumber pangan alternatif dan perlu dikembangkan salah satunya yaitu tanaman garut. Garut merupakan tanaman yang dibudidayakan untuk dimanfaatkan umbinya. Hal tersebut disebabkan karena umbi garut merupakan sumber karbohidrat yang memiliki potensi yang besar untuk dikembangkan di Indonesia (Sukamto et al 2010).

Penambahan pupuk kalium diharapkan dapat meningkatkan produksi dan kualitas umbi tanaman garut. Pertumbuhan dan produksi umbi tergantung pada jenis tanah, ketersediaan $\mathrm{K}$ dalam tanah, banyaknya $\mathrm{K}$ diadsorbsi, dan jumlah $\mathrm{K}$ dalam tanah yang dapat dipertukarkan (Nainggolan dan Tarigan 1992). Tanaman garut masih banyak di biarkan tumbuh secara liar di bawah tegakan pohon jati. Pohon jati dapat mengeluarkan senyawa alellopati, yaitu senyawa yang dapat meracuni tanaman lain yang berada disekitarnya. Matloob et al (2010) mengatakan bahwa alelopati juga dapat digunakan sebagai pengendali gulma dengan menerapkan residu dari gulma atau tanaman alelopati sebaga mulsa air. Proses pertumbuhan tanaman garut yang tumbuh secara liar di bawah tegakan pohon jati dapat terganggu oleh senyawa alellopati dari pohon jati. Syatiriah (2009) menyebutkan bahwa pohon jati merupakan salah satu dari 10 tanaman pada zona estetika kampus Institut Teknologi Sepuluh Nopember yang berpotensi mengeluarkan senyawa alellopati.

\section{METODE PENELITIAN}

Penelitian dilaksanakan di lahan pertanian UNS Jumantono pada bulan Maret - September 2016. Bahan digunakan yaitu tanaman garut (Marantha arundinacea), tanah Alfisol, pupuk kompos, pupuk urea, pupuk SP-36, pupuk $\mathrm{KCl}$, dan seresah daun jati, sedangkan peralatan yang digunakan adalah polibag, cetok, cangkul, gembor, selang, ember, oven, timbangan analitik, penggaris, gunting, pisau cutter, alat tulis, dan jangka sorong.

Penelitian menggunakan Rancangan Acak Kelompok Lengkap (RAKL) dengan 2 percobaan terpisah yaitu pemberian pupuk $\mathrm{KCl}$ dan pemberian seresah daun jati kering. Perlakuan pupuk $\mathrm{KCl}$ yang diberikan pada tanaman garut adalah $\mathrm{KO}\left(0 \mathrm{~g}^{-1} \tan \right), \mathrm{K} 1$ $\left(2,4 \mathrm{~g}^{-1} \tan \right), \mathrm{K} 2\left(4,8 \mathrm{~g}^{-1} \tan \right), \mathrm{K} 3\left(7,2 \mathrm{~g}^{-1} \tan \right)$, dan $\mathrm{K} 4(9,6$ $\left.\mathrm{g}^{-1} \mathrm{tan}\right)$. Perlakuan seresah daun jati yang diberikan pada tanaman garut adalah A0 (0 g/tan), A1 (20 g $\left.{ }^{-1} \tan \right)$, A2 (40 $\left.\mathrm{g}^{-1} \tan \right)$, A3 $\left(60 \mathrm{~g}^{-1} \mathrm{tan}\right)$, dan A4 (80 g hasil pengamatan dianalisis menggunakan analisis ragam (Anova) dengan uji signifikansi $5 \%$ dan apabila terdapat beda nyata dilanjutkan dengan uji jarak berganda Duncan (DMRT) pada taraf 5\%. 
Variabel pengamatan meliputi: tinggi tanaman, jumlah daun, jumlah anakan, rasio akar tajuk, jumlah umbi per tanaman, berat umbi per tanaman, dan ukuran umbi per tanaman.

Perancangan penelitian yaitu dengan menggunakan polibag berukuran $30 \times 60 \mathrm{~cm}$ dan disusun pada jarak tanam 40x40 cm. Media tanah terlebih dahulu dicampur dengan pupuk kompos $3: 1$, lalu diberikan pupuk urea dan SP-36 sebagai pupuk dasar, kemudian dimasukkan ke dalam polibag dan ditanam tanaman garut. Setelah tanaman garut berumur 1 bulan dilakukan aplikasi pupuk KCl dan seresah daun jati sebagai perlakuan.

\section{HASIL DAN PEMBAHASAN}

\section{Pemberian pupuk $\mathrm{K}$ terhadap hasil garut}

\section{Pertumbuhan tanaman garut}

Pertumbuhan dan perkembangan tanaman merupakan proses yang penting dalam kehidupan dan perkembangan suatu species. Pertumbuhan dan perkembangan berlangsung secara terus-menerus sepanjang daur hidup, bergantung pada tersedianya meristem, hasil asimilasi, hormon dan substansi pertumbuhan lainnya, serta lingkungan yang mendukung (Gardner et al 1991).

Salah satu indikator yang digunakan untuk mengukur pertumbuhan tanaman adalah tinggi tanaman, karena tinggi tanaman merupakan ukuran pertumbuhan yang paling mudah dilihat (Sitompul dan Guritno 1995). Berdasarkan uji Anova pemberian pupuk $\mathrm{KCl}$ tidak berpengaruh nyata terhadap rerata tinggi tanaman garut saat umur 12 bulan. Rerata tinggi tanaman tertinggi pada dosis $0 \mathrm{~g} / \mathrm{tan}$ yaitu sebesar $62,60 \mathrm{~cm}$. Rerata tinggi tanaman terendah umur 12 bulan pada dosis $2,4 \mathrm{~g} / \mathrm{tan}$ yaitu $48 \mathrm{~cm}$. Tinggi tanaman tidak mencapai hasil yang maksimal dari pemberian pupuk $\mathrm{KCl}$ disebabkan karena karena rebahnya tanaman induk yang diakibatkan oleh hujan lebat. Hal ini diduga karena tanaman garut yang mempunyai batang semu yang berpelepah dan berserat (Soedibyo 1995), sehingga diduga jika batang tanaman patah maka jaringan tumbuhan akan putus yang menyebabkan metabolisme tanaman menjadi terhambat.

Daun merupakan bagian tanaman yang berfungsi untuk melakukan fotosintesis dan respirasi. Jumlah daun yang semakin banyak dapat mengindikasikan pertumbuhan tanaman tersebut juga baik (Sitompul dan Guritno 1995). Daun sebagai salah satu morfologi tanaman menjadi indikator dalam identifikasi kekurangan hara seperti unsur $\mathrm{K}$ (Kamwean et al 2017). Berdasarkan uji Anova pemberian pupuk kalium tidak berpengaruh nyata terhadap rerata jumlah daun tanaman garut saat umur 12 bulan. Rerata jumlah daun tertinggi mencapai 67,40 helai pada dosis $4,8 \mathrm{~g}^{-1}$ tan, sedangkan rerata jumlah daun terendah yaitu 54,00 helai pada dosis $2,4 \mathrm{~g}^{-1}$ tan. pemberian pupuk kalium dengan dosis tinggi belum tentu dapat diserap tanaman dengan baik, karena pupuk kalium merupakan pupuk anorganik yang banyak mengandung bahan kimia, pemupukan harus disesuaikan dengan jenis pupuk, kesalahan cara pemupukan dan penentuan dosis pupuk akan berakibat kurang baik bagi tanah dan tanaman (Setyamidjaya 1986).

Pertumbuhan dan perkembangan tanaman garut dapat dilihat dari jumlah anakan. Jumlah anakan dapat dijadikan sebagai indikator pertumbuhan tanaman maupun hasil produksi tanaman (Sohel et al 2009). Berdasarkan hasil uji Anova pemberian pupuk kalium tidak berpengaruh nyata terhadap rerata jumlah anakan tanaman garut saat umur 12 bulan. Saat umur 12 bulan rerata jumlah anakan tertinggi sebanyak 14,40 anakan pada dosis $0 \mathrm{~g} / \mathrm{tan}$. Rerata jumlah anakan terendah terdapat pada dosis 2,4 g/tan yaitu 11,20 anakan. Unsur kalium tidak tersedia dalam tanah. Tingkat ketersediaan $\mathrm{K}$ sangat dipengaruhi oleh $\mathrm{pH}$ dan kejenuhan basa. Pada $\mathrm{pH}$ dan kejenuhan basa rendah kalium mudah hilang tercuci, pada $\mathrm{pH}$ netral dan kejenuhan basa tinggi kalium dapat diikat oleh unsur $\mathrm{Ca}$ sehingga unsur $\mathrm{K}$ tersedia dalam tanah (Widowati et al 2011).

Besarnya rasio akar tajuk berkaitan dengan kemampuan absorbsi air oleh tanaman yang meningkat sebagai salah satu mekanisme untuk mempertahankan potensial air yang tetap tinggi pada saat tanaman mengalami kekurangan air (Palupi dan Dedywiryanto 2008). Berdasarkan hasil uji Anova pemberian pupuk kalium tidak bepengaruh nyata terhadap rasio akar tajuk dari tanaman garut. Pemberian pupuk $\mathrm{KCl}$ sebanyak 4,8 g/tan mencapai rasio akar tajuk tertinggi yaitu 0,846. Rasio akar tajuk terendah senilai 0,446 pada dosis 2,4 g/tan. Nilai rasio akar tajuk menunjukkan bahwa berat akar lebih rendah dari berat tajuk. Solichatun (2005) menyatakan bahwa pertumbuhan tajuk lebih digalakkan apabila tersedia unsur nitrogen (N) dan air yang banyak, sedangkan pertumbuhan akar lebih digalakkan apabila nitrogen dan air terbatas.

\section{Hasil tanaman garut}

Pada umumnya umbi garut berwarna putih dan dibungkus oleh daun-daun sisik yang berwarna kecoklatan. Sebagai sumber karbohidrat, komposisi umbi garut sangat didominasi oleh karbohidrat terutama pati. Bahan segar yang baru saja dipanen mengandung pati antara 16 - $18 \%$ dengan kandungan air yang sanga tinggi (Villamayor dan Jukema 1995).

Pemberian pupuk kalium diharapkan dapat meningkatkan produksi tanaman garut. Singh et al (2007) menyatakan bahwa pupuk kalium dapat meningkatkan produksi tanaman herba. Berdasarkan uji Anova pemberian pupuk kalium tidak berpengaruh nyata terhadap rerata jumlah umbi tanaman garut. Rerata jumlah umbi tertinggi sebanyak 26,00 umbi pada dosis $4,8 \mathrm{~g}^{-1}$ tan. Rerata jumlah umbi terendah sebanyak 15,60 umbi pada dosis 7,2 $\mathrm{g}^{-1}$ tan. Unsur $\mathrm{K}$ mudah tercuci pada tanah Alfisol (Arsyad 2006) sehingga tidak dapat diserap oleh tanaman garut.

Hasil produksi tanaman garut dapat dilihat dari berat umbi yang dihasilkan. Pemberian pupuk kalium diharapkan dapat meningkatkan kualitas umbi garut yang dihasilkan. Berdasarkan uji Anova pemberian pupuk $\mathrm{KCl}$ tidak berpengaruh nyata terhadap rerata berat umbi tanaman garut. Rerata berat umbi tertinggi terdapat pada dosis $4,8 \mathrm{~g} \mathrm{~g}^{-1}$ tan senilai 779 gram. Rerata berat umbi terendah pada dosis $7,2 \mathrm{~g}^{-1}$ tan yaitu 469 
gram. Kurangnya ketersediaan $\mathrm{K}$ dalam tanah yang disebabkan pencucian unsur hara oleh air pada media tanam (Perfect et al. 2002) sehingga tanaman garut tidak dapat menyerap unsur $\mathrm{K}$.

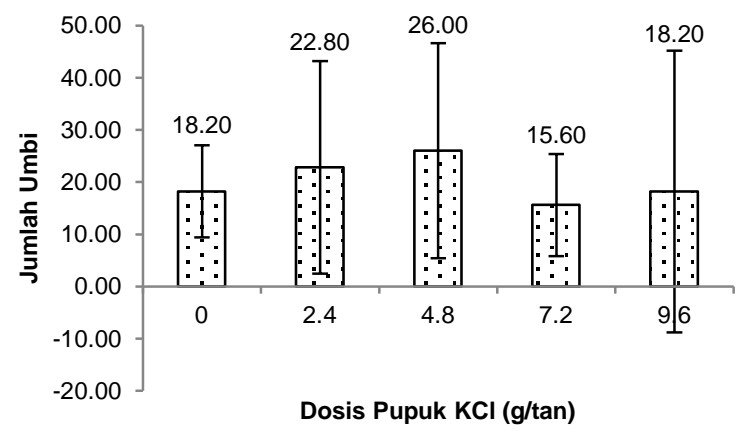

Gambar 1 Pengaruh pemberian pupuk $\mathrm{KCl}$ terhadap rerata jumlah umbi tanaman garut

Umbi garut berasal dari pengisian bahan cadangan makanan pada bagian akar tanaman garut. Indikator untuk mengetahui kualitas produksi tanaman garut adalah ukuran umbi yang diukur berdasarkan panjang dan diameter umbi. Berdasarkan uji Anova pemberian pupuk kalium tidak berpengaruh nyata terhadap rerata panjang umbi dan diameter umbi tanaman garut. Rerata panjang umbi tertinggi terdapat pada dosis 4,8 $\mathrm{g}^{-1} \tan$ senilai $30,66 \mathrm{~cm}$. Rerata berat umbi terendah pada dosis $2,4 \mathrm{~g}^{-1}$ tan yaitu $20,78 \mathrm{~cm}$. Rerata diameter umbi tertinggi terdapat pada dosis pupuk kalium 4,8 g ${ }^{1}$ tan yaitu $1,82 \mathrm{~cm}$. Rerata diameter terendah terdapat pada dosis $7,2 \mathrm{~g}^{-1}$ tan yaitu $1,52 \mathrm{~cm}$. Pupuk kalium tidak sepenuhnya berpengaruh terhadap ukuran umbi, karena perkembangan umbi juga tergantung pada kualitas tanah. Nainggolan dan Tarigan (1992) menyatakan bahwa kualitas umbi juga tergantung pada jenis tanah, ketersediaan $\mathrm{K}$ dalam tanah dan banyaknya $\mathrm{K}$ diadsorbsi, juga jumlah $\mathrm{K}$ tertukar dalam tanah.

\section{Pemberian seresah daun jati terhadap hasil garut}

\section{Pertumbuhan tanaman garut}

Pertumbuhan tanaman dipengaruhi oleh senyawa kimia. Senyawa kimia dapat bersifat mendukung pertumbuhan tanaman dan juga dapat menghambat pertumbuhan tanaman. Salah satu senyawa kimia yang dapat menghambat pertumbuhan yaitu alellopati (Singh et al 2003).

Tinggi tanaman merupakan ukuran tanaman yang sering diamati sebagai indikator pertumbuhan dan sebagai parameter yang digunakan untuk mengukur pengaruh lingkungan atau perlakuan yang diterapkan (Sitompul dan Guritno 1995). Berdasarkan uji Anova pemberian seresah daun jati tidak berpengaruh nyata terhadap rexata tinggi tanaman garut saat umur 12 bulan, namun ulangan perlakuan seresah daun jati berpengaruh nyata terhadap tinggi tanaman garut saat umur 12 bulan. Pada uji lanjutan Duncan perlakuan dosis $40 \mathrm{~g} / \tan$ dan $80 \mathrm{~g} / \tan$ menunjukkan hasil yang berbeda nyata. Rerata tinggi tanaman terendah saat umur 12 bulan pada dosis $40 \mathrm{~g}^{-1} \tan$ yaitu $58,4 \mathrm{~cm}$, sedangkan rerata tinggi tanaman tertinggi pada dosis
$80 \mathrm{~g}^{-1} \tan$ yaitu $81,8 \mathrm{~cm}$. zat alellopati yang terdapat pada seresah daun jati terserap tanaman garut secara optimal sehingga dapat menggangu pertumbuhan tanaman garut yang mengakibatkan indukan tanaman garut rebah. Hal ini sesuai dengan pernyataan Rice (1974) bahwa zat alellopati dapat menghambat pertumbuhan tanaman.

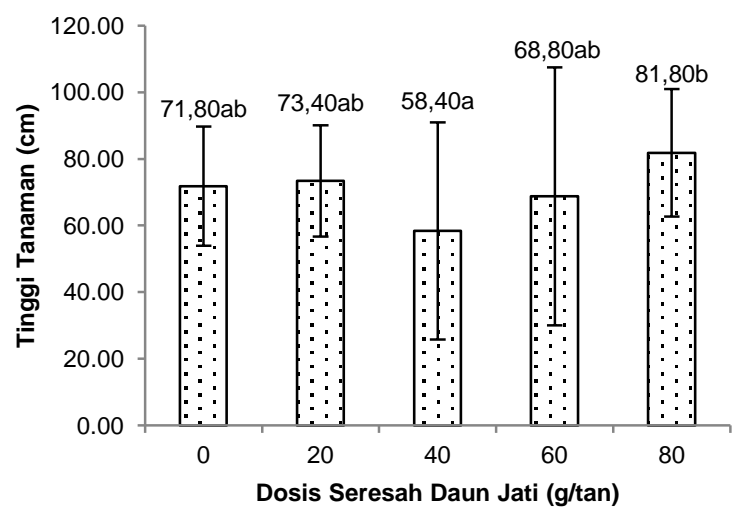

Keterangan: Angka yang diikuti huruf yang sama pada kolom yang sama tidak berbeda nyata pada uji Duncan pada a $5 \%$

Gambar 2 Pengaruh pemberian seresah daun jati terhadap rerata tinggi tanaman garut saat umur 12 bulan

Jumlah daun pada suatu tanaman dapat dijadikan sebagai indikator pertumbuhan tanaman (Sitompul dan Guritno 1995). Berdasarkan uji Anova pemberian seresah daun jati berpengaruh nyata terhadap rerata jumlah daun tanaman garut saat umur 12 bulan. Pada uji lanjutan Duncan dosis $20 \mathrm{~g}^{-1}$ tan berbeda nyata terhadap perlakuan $60 \mathrm{~g}^{-1}$ tan dan $80 \mathrm{~g}^{-1}$ tan. Rerata jumlah daun terendah saat umur 12 terdapat pada dosis $20 \mathrm{~g}^{-1}$ tan yaitu 48,6 helai. Rerata jumlah daun tertinggi terdapat pada dosis $60 \mathrm{~g}^{-1}$ tan yaitu 69,8 helai. Senyawa alellopati terserap oleh tanaman garut sehingga pertumbuhan daun tanaman garut menjadi terhambat. Hal ini sesuai dengan pernyataan Rice (1974) bahwa zat alellopati dapat menghambat pertumbuhan tanaman.

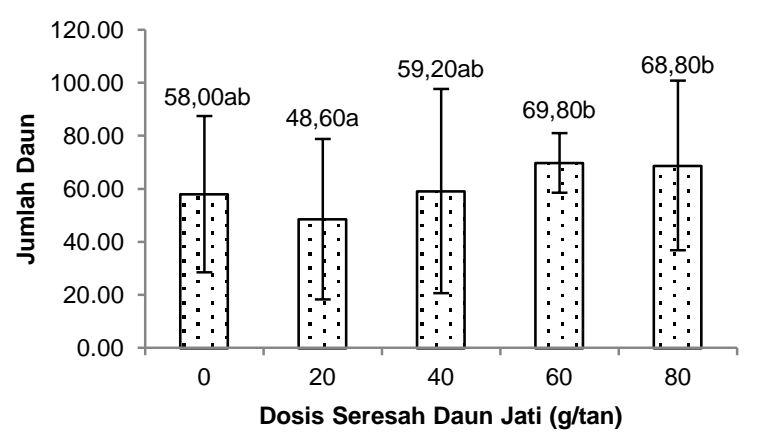

Keterangan: Angka yang diikuti huruf yang sama pada kolom yang sama tidak berbeda nyata pada uji Duncan pada a $5 \%$

Gambar 3 Pengaruh pemberian seresah daun jati terhadap rerata jumlah daun tanaman garut saat umur 12 bulan

Anakan tanaman merupakan tanaman muda yang tumbuh dari pertunasan. Jumlah anakan dapat 
mempengaruhi produktivitas tanaman (Sohel et al 2009). Berdasarkan uji Anova pemberian seresah daun jati tidak berpengaruh nyata terhadap rerata jumlah anakan tanaman garut saat umur 12 bulan. Rerata jumlah anakan terendah senilai 10,40 anakan pada dosis $20 \mathrm{~g}^{-1}$ tan. Rerata jumlah anakan tertinggi senilai 14,00 anakan pada dosis $80 \mathrm{~g}^{-1}$ tan. Alellopati tidak terserap oleh tanaman, karena alellopati larut oleh pergrakan air dalam tanah (Toor et al 2004).

Rasio akar tajuk dapat menunjukkan adanya peristiwa kekurangan air pada tanaman. Sulistyaningsih et al (2005) menjelaskan jika pada tanaman terjadi kekurangan air akan menghambat pertumbuhan tajuk dibandingkan akar. Berdasarkan hasil uji Anova pemberian seresah daun jati tidak berpengaruh nyata terhadap rerata rasio akar tajuk tanaman garut. Rerata terendah terdapat pada dosis $0 \mathrm{~g} / \tan$ sebesar 0,412 gram, sedangkan rerata rasio akar tajuk tertinggi sebesar 0,688 pada dosis $60 \mathrm{~g}^{-1}$ tan. Curah hujan yang tinggi pada masa percobaan menjadi penyebab terlalu banyak air tersedia bagi tanaman, sehingga pertumbuhan tajuk lebih tinggi daripada pertumbuhan akar tanaman.

\section{Hasil tanaman garut}

Umbi garut terbentuk dari rizhoma yang menebal di bawah tanah. Umbi garut merupakan organ tempat penyimpanan bahan cadangan makanan seperti karbohidrat yang dapat dimanfaatkan untuk perkembang biakan tanaman (Klimešová and Klimeš 2007).

Tinggi rendahnya produktivitas tanaman garut dapat dilihat dari jumlah umbi yang dihasilkan oleh tanaman garut. Berdasarkan uji Anova pemberian seresah daun jati tidak berpengaruh nyata terhadap rerata jumlah umbi tanaman garut. Rerata jumlah umbi terendah terdapat pada dosis $0 \mathrm{~g} / \tan$ sebesar 20,20 umbi. Rerata jumlah umbi tertinggi sebesar 29,60 umbi pada dosis 80 $\mathrm{g} / \mathrm{tan}$. Tanaman garut diduga tahan terhadap senyawa alellopati, karena tanaman garut umumnya tumbuh dibawah tegakan pohon jati (Nurhayati et al 2003).

Kualitas umbi tergantung pada proses fisiologi tanaman. Kualitas umbi garut dapat dilihat dari berat umbi yang dihasilkan oleh tanaman garut. Berdasarkan uji Anova pemberian seresah daun jati tidak berpengaruh nyata terhadap rerata berat umbi tanaman garut. Rerata berat umbi terendah terdapat pada dosis $20 \mathrm{~g} / \mathrm{tan}$ yaitu sebesar $791 \mathrm{gram}$. Rerata berat umbi tertinggi terdapat pada dosis $80 \mathrm{~g} / \mathrm{tan}$ sebesar 852 gram. Perubahan sifat kimia alellopati yang dipengaruhi oleh perubahan sifat kimia tanah yang disebabkan mikroorganisme tanah, sehingga alellopati berubah menjadi unsur hara bagi tanaman (Saraswati et al 2007).

Kualitas umbi yang dihasilkan tanaman garut dapat dilihat dari ukuran umbi. Ukuran umbi garut diukur berdasarkan panjang dan diameter umbi. Berdasarkan uji Anova pemberian seresah daun jati tidak berpengaruh nyata terhadap rerata panjang umbi dan diameter umbi tanaman garut. Rerata panjang umbi dengan perlakuan seresah daun jati tidak lebih rendah dari rerata panjang umbi pada dosis $0 \mathrm{~g} / \mathrm{tan}$. Rerata panjang umbi terendah terdapat pada dosis $0 \mathrm{~g} / \mathrm{tan}$ sebesar $24,22 \mathrm{~cm}$. Rerata panjang umbi tertinggi sebesar $32,40 \mathrm{~cm}$ pada dosis $20 \mathrm{~g} \mathrm{~g}^{-1}$ tan. Rerata diameter umbi terendah terdapat pada dosis $20 \mathrm{~g} / \mathrm{tan}$ sebesar $1,60 \mathrm{~cm}$. Rerata diameter umbi tertinggi sebesar 2,32 cm pada dosis $60 \mathrm{~g}^{-1}$ tan. Terjadi penguapan senyawa alellopati pada waktu percobaan. Penguapan alellopati terjadi karena suhu yang tinggi pada lahan percobaan. Penguapan unsur hara juga diungkapan oleh Leiwakabessy (1988) bahwa unsur nitrogen pada media tanam dipengaruhi oleh suhu yang tinggi.

\section{KESIMPULAN DAN SARAN}

\section{Kesimpulan}

Berdasarkan hasil penelitian yang telah diuraikan, dapat disimpulkan sebagai berikut :

1. Perlakuan pemberian pupuk kalium pada tanaman garut tidak berpengaruh nyata terhadap semua variabel pengamatan.

2. Dosis pupuk $\mathrm{KCl} 4,8$ gram/tan cenderung memberikan hasil umbi garut yang paling tinggi, hal ini tercermin pada variabel pengamatan jumlah umbi, berat umbi, panjang umbi, dan diameter umbi.

3. Perlakuan pemberian seresah daun jati pada tanaman garut tidak berpengaruh nyata terhadap semua variabel pengamatan, kecuali tinggi tanaman dan jumlah daun saat umur 12 bulan. Dosis seresah daun jati $40 \mathrm{~g} / \tan$ menghasilkan tinggi tanaman yang lebih rendah dibandingkan dosis seresah daun jati $80 \mathrm{~g} / \mathrm{tan}$. Dosis seresah daun jati $20 \mathrm{~g} / \mathrm{tan}$ menghasilkan jumlah daun yang lebih rendah dibandingkan dosis seresah daun jati $60 \mathrm{~g} / \tan$ dan $80 \mathrm{~g} / \mathrm{tan}$.

4. Dosis seresah daun jati 80 gram/tan cenderung memberikan hasil umbi garut yang paling tinggi, hal ini tercermin pada variabel pengamatan jumlah umbi dan berat umbi.

\section{Saran}

Berdasarkan hasil penelitian yang diperoleh maka saran yang dapat diberikan yaitu penelitian selanjutnya yang sejenis disarankan mengkombinasikan perlakuan pupuk kalium dengan seresah daun jati untuk mendapatkan hasil tanaman garut yang lebih optimal, pemberian pupuk $\mathrm{KCl}$ pada tanah Alfisol sebaiknya dilakukan pelapisan dengan menggunakan bahan organik agar unsur kalium tidak mudah tercuci dan tersedia bagi tanaman terutama pada daerah perakaran, seresah daun jati dapat dijadikan sebagai sumber bahan organik oleh tanaman yang mempunyai umur panjang seperti tanaman garut.

\section{DAFTAR PUSTAKA}

Arsyad S. 2006. Konservasi tanah dan air. Bogor(ID): IPB Press.

Gardner FP, Pearce RB, Mitchell RL. 1991. Fisiologi tanaman budidaya. Terjemahan: Herawati Susilo. Jakarta(ID): UI Press.

Kamwean P, Chaisan T, Thobunluepop P, Phumichai C, Bredemeier M. 2017. Changing of morphological characteristic and biomass properties in Pennisetum 
purpureum by colchicine treatment. J Agronomy. 16 (1) : 23-31.

Klimešová J, Klimeš L. 2007. Bud banks and their role in vegetative regeneration - A literature review and proposal for simple classification and assessment. Perspectives in Plant Ecology, Evolution and Systematics 8: 115-129.

Leiwakabessy FM. 1988. Kesuburan tanah. Bogor(ID): IPB Press.

Matloob A, Khaliq A, Farooq M, Cheema ZA. 2010. Quantification of allelopathic potential of different crop residues for the purple nutsedge suppression. Pakistan. J Weed Science Research. 16(1):112.

Nainggolan P, Tarigan D. 1992. Pengaruh sumber dan dosis pupuk kalium terhadap hasil dan mutu umbi kentang. J Hortikultura 2. Hal : 781-787.

Nurhayati H, Sudiarto, Gusmaini, Rahardjo M. 2003. Daya hasil umbi-umbian dan pati beberapa aksesi garut (Marantha arundinacea L.) pada beberapa tingkat naungan. J IImiah Pertanian. IX(2): 17-25.

Palupi ER, Dedywiryanto Y. 2008. Kajian karakter toleransi cekaman kekeringan pada empat genotipe bibit kelapa sawit (Elaeis guineensis Jacq). Bul Agron. 36(1): 24-32.

Perfect EMC, Sukop, Haszler GR. 2002. Prediction of dispersivity for undisturbed soil columns from water retention parameters. J Soil Science Society of America. Pp. 696-701.

Rice EL. 1974. Allelopathy. New York(US): Acad Press.

Saraswati S, Adolfsen B, Littleton JT. 2007. Characterization of the role of the Synaptotagmin family as calcium sensors in facilitation and asynchronous neurotransmitter release. Proceedings of the National Academy of Sciences of USA 104(35): 14122-14127.

Setyamidjaya D. 1986. Pupuk dan pemupukan. Jakarta(ID): Simplex.

Singh HP, Batish DR, Kohli RK. 2003. Allelopathic interaction and allelochemicals: new possibilities for sustainable weed management. Critical Reviews in Plant Sciences. 22: 239-311.

Sitompul SM, Guritno B. 1995. Analisis pertumbuhan tanaman. Yogyakarta(ID): Gadjah Mada University Press.

Soedibyo M. 1995. Alam sumber kesehatan, manfaat dan kegunaan. Jakarta(ID): Balai Pustaka.

Sohel MAT, Siddique MAB, Asaduzzaman M, Alam MN, Karim MM. 2009. Varietal performance of transplant aman rice under different hill densities. Bangladesh. J Agril Res. 34(1): 33 - 39.

Solichatun, Anggarwulan E, Mudyantini W. 2005. Pengaruh ketersediaan air terhadap pertumbuhan dan kandungan bahan aktif saponin tanaman ginseng jawa (Talinum paniculatum Gaertn.). J Biofarmasi. 3 (2): 47-51.

Sulisyaningsin E, Kurniasih B dan Kurniasih E. 2005. Pertumbuhan dan hasil Caisin pada berbagai warna sungkup plastik J IImu Pertanian. 12: 65-76.

Syatiriah H. 2009. Inventarisasi tanaman Berpotensi alelopati di kampus ITS Sukolilo Surabaya. Skripsi. Surabaya(ID): Institut Teknologi Sepuluh Nopember.

Torr GS, Condron LM, Cameron KC. 2004. Seasonal fluctuations in phosphorus loss by leaching from a grassland soil. J Soil Science Society of America 68: 1429-1436.

Villarnayor FG, Jukema J 1995. Marantha arundinacea L. in plant resources of South-East Asia 9, PlantsYielding non-seed carbohydrates. Prosea.

Widowati, Utomo WH, Soehono LA, Guritno B. 2011. Effect of biochar on the release and loss of nitrogen from urea fertilization. J Agriculture and Food Technology 1: 127-132. 